\title{
A Nova Rota da Seda e seus desafios securitários: os Estados Unidos e a contenção do eixo Sino-Russo
}

\section{The New Silk Road and its security challenges: the United States and the containment of the Sino-Russian axis}

Diego Pautasso'

DOI: 10.5752/P.2317-773X.2019v7.n2.p85

Recebido em: 14 de julho de 2018

Aceito em: 22 de outubro de 2018
1. Doutor e mestre em Ciência Política e graduado em Geografia pela UFRGS. Professor do Colégio Militar de Porto Alegre. Autor do livro China e Rússia no Pós-Guerra Fria, 2010, Ed. Juruá. E-mail: dgpautasso@gmail.com. Porto Alegre/ Brasil. ORCID: 0000-0002-2393-1903. (ID)

Resumo:

O presente artigo analisa os desafios securitários que se colocam para a Belt and Road Initiative (BRI), também chamada de Nova Rota da Seda. Entendemos que a iniciativa de Beijing representa a etapa regional do projeto chinês de globalização e, com efeito, tensiona com a primazia global estadunidense. Dessa forma, sugerimos que a estratégia dos Estados Unidos passa pela conformação de um arco de contenção do eixo sino-russo. Isso porque as relações entre China e Rússia têm definido o ritmo, o conteúdo e a forma dos processos de integração da Eurásia. Ou seja, a outrora política de contenção soviética no contexto da Guerra Fria ganha novos contornos e desafios mais abrangentes para os Estados Unidos. Com efeito, não seria demais supor que, tanto o êxito da iniciativa chinesa de integração euroasiática, quanto os rumos da transição sistêmica em curso dependem do desafio securitário representado pela projeção de Washington sobre esta região.

Palavras-chave: Nova Rota da Seda, Contenção, Eixo Sino-Russo, Estados Unidos

\section{ABSTRACT:}

This article analyses the security challenges facing the Belt and Road Initiative (BRI), also called the New Silk Road. We understand that the Beijing initiative represents the regional stage of the Chinese globalization project and, in fact, it is in tension with the global primacy of the United States. Thus, we suggest that the strategy of the United States involves the formation of a containment arc of the Sino-Russian axis. This is because relations between China and Russia have defined the rhythm, content and form of Eurasia's integration processes. In other words, the former Soviet containment policy in the context of the Cold War gains new outlines and broader challenges for the United States. Indeed, it would not be too much to suppose that both the success of the Chinese Eurasian integration initiative and the direction of the ongoing systemic transition depend on the security challenge posed by Washington's projection for this region.

Keywords: New Silk Road, Containment, Sino-Russian Axis, United States 
Introdução

A Iniciativa OBOR (One Belt, One Road), também conhecida como Nova Rota da Seda, foi divulgada no segundo semestre de 2013 pelo presidente chinês Xi Jinping. Depois chamada de Belt and Road Initiative (BRI), logo foi objeto, em maio de 2017, do seu primeiro Fórum (Belt and Road Forum) - a ser realizado bianualmente. Trata-se de um gigantesco projeto de integração eurasiático assentado em infraestrutura (transporte, comunicação e energia), abrindo caminho para investimentos produtivos e comércio regional.

A Nova Rota da Seda representa o amadurecimento da inserção global da China ao transitar da diplomacia de baixo perfil de Deng Xiaoping para uma crescente assertividade internacional. Mais do que vetor da política externa chinesa, a integração eurasiática poposta por Beijing representa a etapa regional do projeto chinês de globalização. Esse projeto recria o sistema sinocêntrico e tensiona com a primazia global estadunidense, convertendo-se no epicentro de uma contradição crucial para compreender os desdobramentos da transição sistêmica em curso. Há, nesse quadro, estratégias distintas em disputa entre potências (Estados Unidos e China, sobretudo) cuja acomodação e conflitos são incertos.

Nesse artigo, pretendemos explorar a política estadunidense de contenção da integração eurasiática liderada pela China em estreita relação com a Rússia. Na verdade, Washington não esperava que aproximação sino-americana dos anos 1970 e o colapso soviético - seguido do desmonte da Rússia nos anos 1990 - culminassem num ambicioso processo de integração eurasiático. Sugerimos, de um lado, que a integração eurasiática recria a percepção de ameaça aos interesses anglo-saxão originalmente formulada com o conceito de heartland mackinderiano e, por outro, que se atualiza a política de contenção desta região aos moldes da Guerra Fria. É perceptível que - a despeito da posse de capacidades militares convencionais e inclusive nucleares - a estratégia dos Estados Unidos tem mobilizado todos os meios para lidar com os países desafiantes em questão. Em outras palavras, o eixo sino-russo é objeto de uma plêiade de ações voltada a sua contenção, proporcionando grandes desafios securitários cujos desdobramentos serão decisivos para a conformação da Nova Rota da Seda.

Para tanto, o artigo foi organizado da seguinte forma. Na primeira seção pretendemos traçar um breve panorama sobre as disputas pela Eurásia. Na segunda, abordamos a escalada intervencionista dos Estados Unidos na Eurásia no século XXI. E, por fim, buscamos demonstrar que o êxito da Nova Rota da Seda depende da capacidade de Moscou e Beijing lidarem com o recrudescimento de desafios securitários no seu entorno estratégico.

China, Rússia e integração da Eurásia: disputas e contenções

O conceito de Eurásia é polissêmico e foi ressignificado ao longo da história (VASYLIEVA; LAGUTINA, 2016). De todo modo, podemos definir como Eurásia esta vasta região entre o Oriente Médio, cruzando a Ásia Central, até a China, cujo papel na história da humanidade tem 
sido central. Como destaca Diamond (2009), as principais espécies animais e vegetais domesticadas eram eurasianas, favorecendo a revolução agrícola através da oferta de carne, leite, lã, couro, transporte, força de trabalho (moinhos, arado), adubo, etc. As transformações agropecuárias permitiram a produção de excedentes, formação de cidades, surgimento de escrita, desenvolvimento de técnicas e armas, conformação de organizações políticas e até fortalecimento da imunidade. Por estas razões se desenvolveram algumas das mais longevas e complexas civilizações, como chinesa, indiana, persa, turca, mongol, russa, entre outras. Também foi local de surgimento e difusão das maiores religiões, como zoroastrismo, as três abraâmicas monoteísta (judaísmo, cristianismo e islamismo), além de hinduismo, budismo, xintoísmo e diversas outras.

Aliás, a primeira grande rede comercial transcontinental no mundo foi a Rota da Seda. Extensas e diversas rotas que ligavam a Ásia Oriental ao Mediterrâneo, passando pelo Sul da Ásia, Ásia Central e Oriente Médio. Sobreviveu aos sobressaltos e colpaso dos Impérios Han e Romano, atingindo seu ápice quando o Império Bizantino e o Império Tang floresceram. Além de mercadorias, suas rotas transacionaram novas ideias, religiões e material genético (LIU, 2010). Pode-se dizer que foi o embrião dos atuais processos de integração global.

Como destaca Amin (2006), entre essas civilizações, a China representou o seu centro mais vigoroso e contínuo nos últimos dois milênios - interrompidos apenas por desordens nos períodos interdinásticos. De acordo com ele, no início da era cristã, tinha $28 \%$ da população mundial, se mantendo até 1700 nessa proporção, até alcançar 35\% no início do século XIX. A China era um epicentro de trocas de mercadorias, tecnologias, ideias, através de diversas rotas da seda. As regiões chinesas de Gansu e Xinjiang (Kashgar) eram um dos pontos de partida, cruzando a Ásia Central (via Samarkand, Bokhara e Khiva, vales do Fergana, do Syr e do Amou Daria), até chegar à Pérsia, e, depois, mercados europeus - os quais eram, até o ano 1000, uma periferia atrasada do sistema pré-moderno (AMIN, 2006, p. 47-8; 50). Aliás, o peso demográfico da China fazia com que o Império do Meio representasse cerca de 32,8\% da produção manufatureira mundial em 1750, ante $1,9 \%$ do Reino Unido - mesmo que com níveis per capita de industrialização similares, 8 e 10 respectivamente (KENNDEY, 1989, p. 148). Após o ciclo de dominação, os pesos demográfico e econômico despencam em relação ao total mundial: a população passa de $36,6 \%$ em 1820 para $21,6 \%$ em 1950 , o PIB de $33 \%$ para $4,6 \%$ e o PIB per capita de $50,2 \%$ para $7,1 \%$ do total da Europa Ocidental e ramificações do Ocidente no mesmo período (NAYYAR, 2014, p. 37).

A Rússia, por sua vez, é um país que se formou a partir da extensão de seus domínios territoriais originalmente centrados num núcleo de ocupação na Europa, aproximadamente entre Moscou e Kiev. Após um período sob controle dos povos mongóis (1240-1480), os povos eslavos russos experimentam rápida expansão em todas as direções, do centro da Europa à Ásia Oriental, do Báltico ao Cáucaso e deste à Ásia Central. Na virada dos séculos XIX-XX, o Império Russo tinha cerca de 22 milhões de $\mathrm{km}^{2}, 130$ milhões de habitantes e mais de 100 grupos étnicos. Evidentemente, essa dinâmica territorial foi permeada por conflitos e disputas importantes, 
sobretudo com a Grã-Bretanha, tanto na Criméia quanto no Indostão em função do chamado Grande Jogo. Como sublinha Trenin (2002, p. 1), suas fronteiras têm definido a cultura e a identidade internacional da Rússia.

A formação dos Estados modernos e a penetração de potências extra regionais intensificaram a competição e os conflitos na Eurásia. A revolução russa (1917) e o subsequente estabelecimento da União Soviética (1922) fez surgir uma experiência socialista desafiante no epicentro da massa territorial eurasiana. Paradoxalmente, atualizava o temor anglo-saxão pelo controle do heartland originalmente inspirado no poder napoleônico e depois replicado com a experiência nazista. É por esta razão que os Estados Unidos formularam a Doutrina da Contenção como vetor da política externa no Pós-Guerra, inspirada no famoso artigo de Kennan, em 1947, na Foreign Affairs e no documento do Conselho de Segurança Nacional (NSC-68), por exemplo (KISSINGER, 1997, p. 528-559). A criação da Doutrina Truman e do Plano Marshall, bem como das organizações militares no entorno soviético, tais como a OTAN (Organização do Tratado do Atlântico Norte), a OTASE (Organização do Tratado do Sudeste Asiático) e o CENTO (Organização do Tratado Central), assim como as alianças militares bilaterais com Japão, Coreia do Sul, Taiwan e Filipinas, representaram o cerco e a contenção da União Soviética (URSS). Não por acaso, se correspondem às três frentes estratégicas basilares de contenção do Centro Geoestratégico (Bloco Soviético): Extremo Ocidente, Sul Populoso e Extremo Oriente (BRZEZINSKI, 1987, p. 51).

Durante a Guerra Fria foram desencadeadas diversas intervenções no entorno soviético, incluindo Grécia, Península Coreana, Indonésia, Vietnã, entre outros. Além disso, os serviços de inteligência foram parte central da política internacional e das guerras políticas e econômicas. A política de conteção da influência soviética era, contudo, global, como ilustram os casos de patrocínio de guerrilhas anticomunistas pelos Estados Unidos na Nicarágua (Contras), Afeganistão (Al Qaeda), Angola (Unita) e Moçambique (Renamo) nos anos 1980 emblemáticas da estratégia de guerra por procuração (proxy war). Aliás, nesse contexto foi desencadeado a primeira onda de golpes de Estado, utilizando-se amplamente das forças militares sem, contudo, abrir mão de outros elementos. Ou seja, o patrocínio político-diplomático dos Estados Unidos e seus aliados dava-se por meio da Doutrina de Segurança Nacional, da promoção da retórica anticomunista pela grande mídia e da indústria cultural, da instrumentalização dos militares na Escola das Américas no Panamá, etc. Nesse sentido, a desestabilização interna, com a espiral inflacionária, o denuncismo moralista da corrupção pelos setores conservadores, a paralisia institucional e a crise econômica foram pré-condições construídas para a efetivação dos golpes militares (LOSURDO, 2016). Em outras palavras, combinado ao cerco militar, desencadearam operações subterrâneas ao mobilizar todo um sistema de inteligência para lograr objetivos estratégicos em outros países. Por um lado, havia financiamento de órgãos de mídia, ONGs, partidos, sindicatos, movimentos sociais, etc., de modo a moldar a opinião pública com (des)informação, por outro, ações com recurso à força, patrocinando, treinando e oferecendo informações a grupos insurgentes de toda ordem (de paramilitares a guerrilhas e organizações terroristas) para fomentar guerras civis, assassinatos, sabotagens, etc. 
Enfim, a Eurásia foi objeto de diversas cisões e rivalidades sobrepostas durante a Guerra Fria. Primeiramente, aquela que configurou a estrutura da ordem bipolar, hegemonizada por Estados Unidos e seu polo desafiante, a União Soviética. Contudo, outra cisão se entrelaçou à ordem bipolar como decorrência da ruptura sino-soviética a partir dos anos 1960. As rupturas no bloco socialista foram, aliás, habilmente exploradas por Washington, sobretudo quando da aproximação com Beijing na virada dos anos 1960-70. Inclusive, não é possível compreender o desfecho da Guerra Fria, a nova estratégia de inserção internacional chinesa pós-Reformas e a primazia estadunidense a partir dos anos 1990 sem dar centralidade aos conflitos sino-soviéticos.

2.Intervencionismo estadunidense e contenção na Eurásia

Para lançar luzes sobre as estratégias estadunidenses de contenção do processo integrativo da Eurásia, convém uma breve retomada das estratégias de Washington para tentar recompor sua hegemonia no Pós-Guerra fria. Com a situação momentânea de unipolaridade experimentada pelos Estados Unidos nos anos 1990, desencadeou-se uma escalada intervencionista, combinada com a ampliação de sua infraestrutura militar global, notadamente a expansão da OTAN e de suas bases militares ao redor do mundo. Enquanto isso, diversos discursos da globalização superestimaram o desaparecimento das grandes cisões políticas e interestatais em favor de um mundo plano (FRIEDMAN, 2009), de uma sociedade em rede (CASTELLS, 1999) ou de uma cibercultura (LEVY, 1999) - para ficar em poucos exemplos. Algumas leituras subestimam o papel dos Estados e das estruturas hegemônicas de poder. Mais do que isso, subestimam que o poder e a política são conformados por um tênue limite entre o legal e o ilegal, mobilizando diversos meios e instrumentos, violentos ou não, explícitos ou ocultos, para lograr seus objetivos geopolíticos e geoeconômicos. Em outras palavras, a retórica da globalização como inexorável integração dos mercados liberalizados subsumia diante da hipertrofia político-militar dos Estados Unidos - com seu orçamento de defesa para o ano fiscal de 2019 alcançando mais de US\$ 686 bilhões de dólares. ${ }^{2}$

Esse montante orçamentário ilustra a trajetória da superpotência (Estados Unidos), no qual coerção e consentimento, guerra e diplomacia, forças e instituições têm feito parte da sua política internacional. As novas guerras do século XXI - por vezes chamadas de guerras híbridas, conflitos de quarta e quinta geração, tribloco, compostos, irrestritos e ilimitados entre a população, complexos-irregulares e não-lineares - refletem como os conflitos se tornam mais complexos, seja do prisma dos atores envolvidos (Estados, grupos guerrilheiros e terroristas, redes criminosas ou empresas militares privadas); dos meios utilizados (as armas simples e acessíveis ou sofisticados sistemas de armas ou tecnologias de dupla utilização), das táticas empregadas (ações convencionais limitados, o terrorismo, insurgência, guerrilheiros ou operaçõesinformações), dos cenários escolhidos (de áreas urbanas e densamente povoadasparalugares remotos ou inacessíveis), dos multiplicadores utilizados (GPS ou redes sociais) e/ou fontes de financiamento (PIELLA, 2014, p. 2-3). Não obstan-
2. Em 2001, no ano dos atentados às Torres Gêmeas, o orçamento era de 316 bilhões de dólares; um crescimento de mais de $117 \%$ em menos de uma década. Isso ilustra o papel do complexo industrial militar na condução das ações internacionais de Washington, indiferente ao governo e partido à frente da Casa Branca. Para detalhes, ver dados oficiais do Departamento de Defesa disponível em: <https://dod.defense.gov/ Portals/1/Documents/pubs/FY2019-Budget-Request-Overview-Book.pdf > 
3. Ver série de reportagens no The Guardian disponível em: <http://www.theguardian.com/world/interactive/2013/ nov/01/snowden-nsa-files-surveillance-revelations-decoded\#section/1>

4. Há diversas fontes, como The Bureau of Investigative Journalism (https:// www.thebureauinvestigates.com/ projects/drone-war) ou os Drone Papers do The Intercept (https://theintercept. com/drone-papers/

5. Ver estudo em que aprofundamos este argumento em (PAUTASSO; AZERE-

D0, 2011). te a polissemia conceitual e as novas técnicas empregadas, o fato é que as guerras historicamente mobilizaram violência empregada por atores estatais e não-estatais, combinando técnicas, capacidades e recursos para atingir os seus objetivos.

Deve-se reconhecer que não se trata propriamente de uma novidade, pois o século XX também foi repleto de guerras não-convencionais (entre Estados), irregulares e assimétricas, e com intensas operações subterrâneas, sobretudo depois da criação das agências de inteligência das grandes potências, como destacamos. A globalização não provocou o fim dos Estados, ao contrário, mas potencializou os mecanismos de inteligência e guerra, assim como a assimetria entre os países, com as tecnologias desenvolvidas pela Terceira Revolução Industrial (Técnico-Científica) e agora a Indústria 4.0. Por um lado, basta ver a ampliação da capacidade de espionagem lograda pela NSA a partir das denúncias de Edward Snowden. ${ }^{3}$ Segundo ele, o esquema de espionagem de e-mails, cartões de crédito e ligações telefônicas operam em conjunto com empresas de telecomunicações utilizando-se do programa PRISM (de monitoramento em tempo real da Internet).

A novidade talvez resida no fato de que os novos meios tecnológicos para fazer a guerra ampliam as assimetrias, como ilustram bem o caso dos drones. A escalada de bombardeios com aviões não tripulados no Afeganistão, Paquistão, Iraque, Síria, Líbia, Iêmen e Somália tem causado milhares de mortes, em sua esmagadora maioria de civis. ${ }^{4}$ Evidentemente, trata-se de guerras encobertas de proporções globais capazes de amplificar de forma inédita a capacidade dos Estados Unidos, enquanto fragiliza dramaticamente o direito e as organizações internacionais.

Nesse sentido, como destaca Losurdo (2010), depois do 11 de Setembro de 2001, a ameaça difusa do terrorismo e do fundamentalismo legitimou uma escalada intervencionista em nível global (Guerra ao Terror), mesmo sem a autorização do Conselho de Segurança da ONU para a invasão do Iraque (2003), por exemplo, cujo resultado é o enfraquecimento das soberanias e das organizações multilaterais. Ao mesmo tempo em que perseguia Bin Laden, Washington ampliava sua presença física em diversas regiões (bases militares); realizava ataques com drones e intensificava ações da inteligência; promovia prisões, campanha de kill/capture e contratos com mercenários; apoiava grupos extremistas na Síria e na Líbia; e financiava entidades públicas e privadas (National Endowment for Democracy, USAID, Freedom House, Open Society e outras) para promoverem o regime change (BANDEIRA, 2013). O poder estadunidense reside justamente na capacidade de mobilizar de maneira articulada o hard e o soft power, entrelaçando a atuação de agências de espionagem, agências de ajuda e cooperação, think thank, agências de comunicação e empresas privadas. Não é trivial decifrar como Washington mobiliza seus múltiplos instrumentos para lograr seus objetivos políticos e estratégicos.

De todo modo, parece claro que estamos diante de uma segunda onda de golpes de estado, como destaca Losurdo (2016). Isto é, tem-se ampliado os meios de isolamento e criminalização de governos e países, bem como a mobilização de campanhas multimidiáticas voltadas a criar fatos políticos para legitimar guerras humanitárias (ou de responsabilidade de proteger) - como ilustrou o caso Líbio5. Por um lado, as novidades táticas 
incluem novas mídias ao longo da Psywar e PsyOps; ou seja, internet, celulares, facebook, twitter, redes sociais, se tornaram um instrumento essencial da projeção de poder da grande potência que detém os principais meios. A crescente variedade e sofisticação dos meios de comunicação permite provocar indignações tão poderosas que resulte arrebatadora. Por outro, as novidades políticas evoluem das ditaduras militares imunes à opinião pública à instauração de democracias sob a proteção de Washington e Bruxelas. Para além da superioridade militar decorrente da Revolução nos Assuntos Militares, há um entrelaçamento entre novidades táticas e novidades políticas que multiplicam a capacidade de atuação das grandes potências em levar ao fim seus objetivos políticos e estratégicos (LOSURDO, 2016, p.1256; 153; 188-91). Aliás, o documentário Guerra Suja (Dirty War) ${ }^{6}$ exemplifica como as ações militares têm vitimado a população civil em outros países.

As políticas de regime change envolvem 'revoluções coloridas', Primavera Árabe e 'golpes constitucionais'. Os 'golpes constitucionais', como ocorrido em Honduras (2009), Paraguai (2012) e Brasil (2016), dispensa a força física dos tradicionais golpes militares em favor de golpes constitucionais; preservam o efeito-legalidade das instituições e suas regras; e subvertem a ordem destituída mantendo verniz de legitimidade (SANTOS, 2017, p. 12-6). Ou seja, governos eleitos são interrompidos por meio de mecanismos autoritários envoltos em rotinas democráticas, de modo que o arranjo legal se torna fonte de exceção e não de Direito (SERRANO, 2016). As práticas típicas de Estados de exceção são realizadas sem a interrupção do Estado democrático. Ou melhor: os Estados Pós-Democráticos se tornam a face política da lógica neoliberal; a desconstitucionalização restringe os limites do poder, se associando à tradição autoritária e à erosão do tecido social ante o individualismo consumista (CASARA, 2017).

Segundo Korybko (2015), essas mudanças políticas não podem ser entendidas sem recorrer ao conceito de guerra híbrida. De acordo com o autor, os Estados Unidos estão buscando uma "abordagem adaptativa para mudança de regime que combina revoluções coloridas e guerra não-convencional em uma estratégia unificada". A origem desta estratégia, segundo o autor, foi o pensamento de Brzezinski quando este propôs empregar o caos dirigido nos Balcãs Eurasiano. Isto é, guerras por procuração se entrelaçam com as 'revoluções coloridas' e a Primavera Árabe na medida em que exploram técnicas psicológicas de massa para subverter a autoridade do governo alvo através de tecnologia da informação-comunicação e suas redes sociais. À desestabilização, segue-se a guerra não-convencional utilizando-se de meios mais letais para lograr a mudança de regime (KORYBKO, 2015, p. 32; 52-3; 69; 76).

No caso da Ásia, o retorno da Rússia sob a liderança de Vladimir Putin (presidente da Rússia em duas ocasiões, de 1999 a 2008 e retornando ao Kremlin desde 2012) e a ascensão irrefreável da China criaram novos desafios à estratégia geopolítica dos Estados Unidos, sobretudo com o lançamento da Nova Rota da Seda. Aliás, o National Military Strategy, ${ }^{7}$ de 2015, dos Estados Unidos, não titubeia em afirmar que uma de suas principais ameaças securitárias são 'países revisionistas' da ordem mundial, nomeadamente China, Rússia, Irã e Coréia do Norte. Todos esses países são objeto ou de embargos e sanções e/ou contenção através de conflitos no entorno regional. Mais recentemente, o próprio Obama declarou ${ }^{8}$, em
6. Ver detalhes sobre o documentário na resenha da Folha de São Paulo disponível em: <http://www1.folha.uol.com.br/ ilustrada/2014/02/1417264-concorrente-ao-oscar-guerras-sujas-e-exibido-em-canal-pago.shtml>

7. Cabe a leitura do documento do governo dos EUA, disponível em: <http:// www.jcs.mil/Portals/36/Documents/ Publications/2015_National_Military_ Strategy.pdf>.

8. Ver reportagem da Sputnik Brasil disponível em: <http://br.sputniknews.com/ portuguese.ruvr.ru/news/2014_05_31/ Obama-nomeia-Russia-e-China-como-principais-adversarios-potenciais-dos-EUA-6275/> 
9. Ver documento da própria ASEAN, disponivel em: <http://www.asean.org/ storage/images/2015/October/outreach-document/Edited\%20RCEP.pdf> seu discurso perante os graduados da Academia de West Point, que Rússia e China são potenciais ameaças militares. Resta, pois, avaliar quais os desafios securitários os Estados Unidos estão dispostos a empregar para lidar com o desafio sistêmico decorrente da conformação da Nova Rota da Seda sob liderança chinesa.

\section{Nova Rota da Seda e seus desafios securitários}

O projeto chinês de globalização nucleado pela Nova Rota da Seda está articulado a outras iniciativas de integração regionais, notadamente a Organização para a Cooperação de Xangai (OCX), União Econômica Eurasiática (UEE) e ASEAN. A OCX, alargada com Índia e Paquistão (2017), além de 4 Estados observadores (Afeganistão, Belarus, Irã, Mongólia) e 6 Parceiros de Diálogo (Azerbaijão, Armênia, Camboja, Nepal, Turquia, Sri Lanka), tem assumido protagonismo regional (Mapa 1). Começou com prioridade securitária, como ilustra a Estrutura Regional Anti-Terrorismo (RATS-2002), mas tem avançado para as demais dimensões políticas e econômicas. A UEE tem fortalecido a presença regional da Rússia, com essa organização voltada à integração econômica, com países como Armênia, Bielorrússia, Cazaquistão e Quirguistão. A ASEAN também tem desenvolvido mecanismos de aprofundamento e ampliação, como o Regional Comprehensive Economic Partnership (RCEP), num acordo de livre comércio com os dez membros do bloco e mais seis da região (Austrália, China, Índia, Japão, Coreia do Sul e Nova Zelândia) firmado em 2012 $2^{9}$; bem como o Free Trade Area for the Asia Pacific (FTAAP).

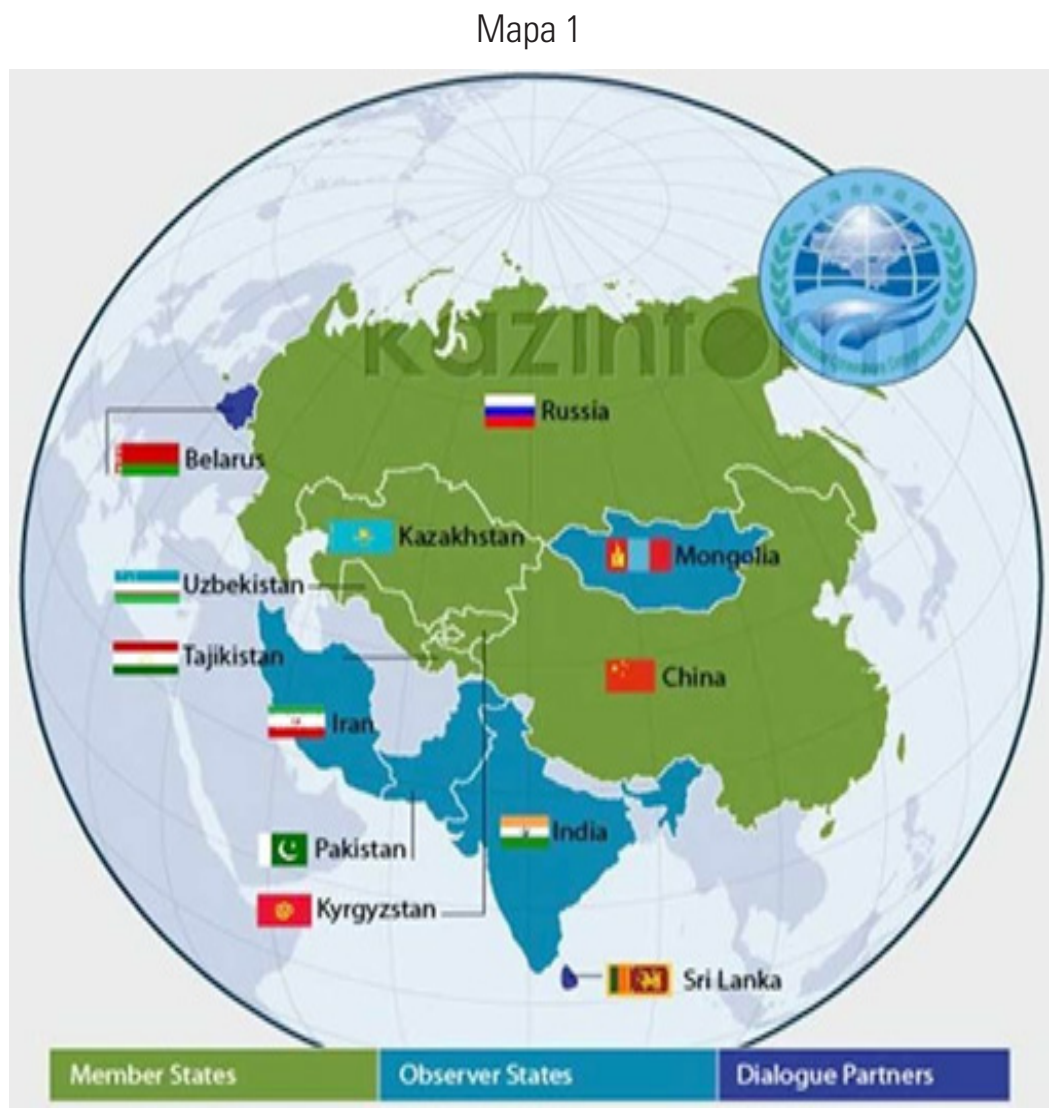

Fonte: Shanghai Cooperation Organization. 
Nesse sentido, a iniciativa chinesa da Nova Rota da Seda vem a ser mecanismo de consolidação desses processos institucionais da Eurásia. Além de ter em seu núcleo a China, principal potência emergente, e Rússia, ainda potência geopolítica (territorial, militar e energética), esta iniciativa de Beijing envolve cerca de 65 países que representam coletivamente mais de $30 \%$ do PIB global, $62 \%$ da população e $75 \%$ das reservas de energia conhecidas, conforme o Banco Mundial. ${ }^{10}$

Mapa 2 - Nova Rota da Seda (Belt and Road Initiative)
10. Ver informações do Banco Mundial, disponível em: https://www.worldbank. org/en/topic/regional-integration/brief/ belt-and-road-initiative.

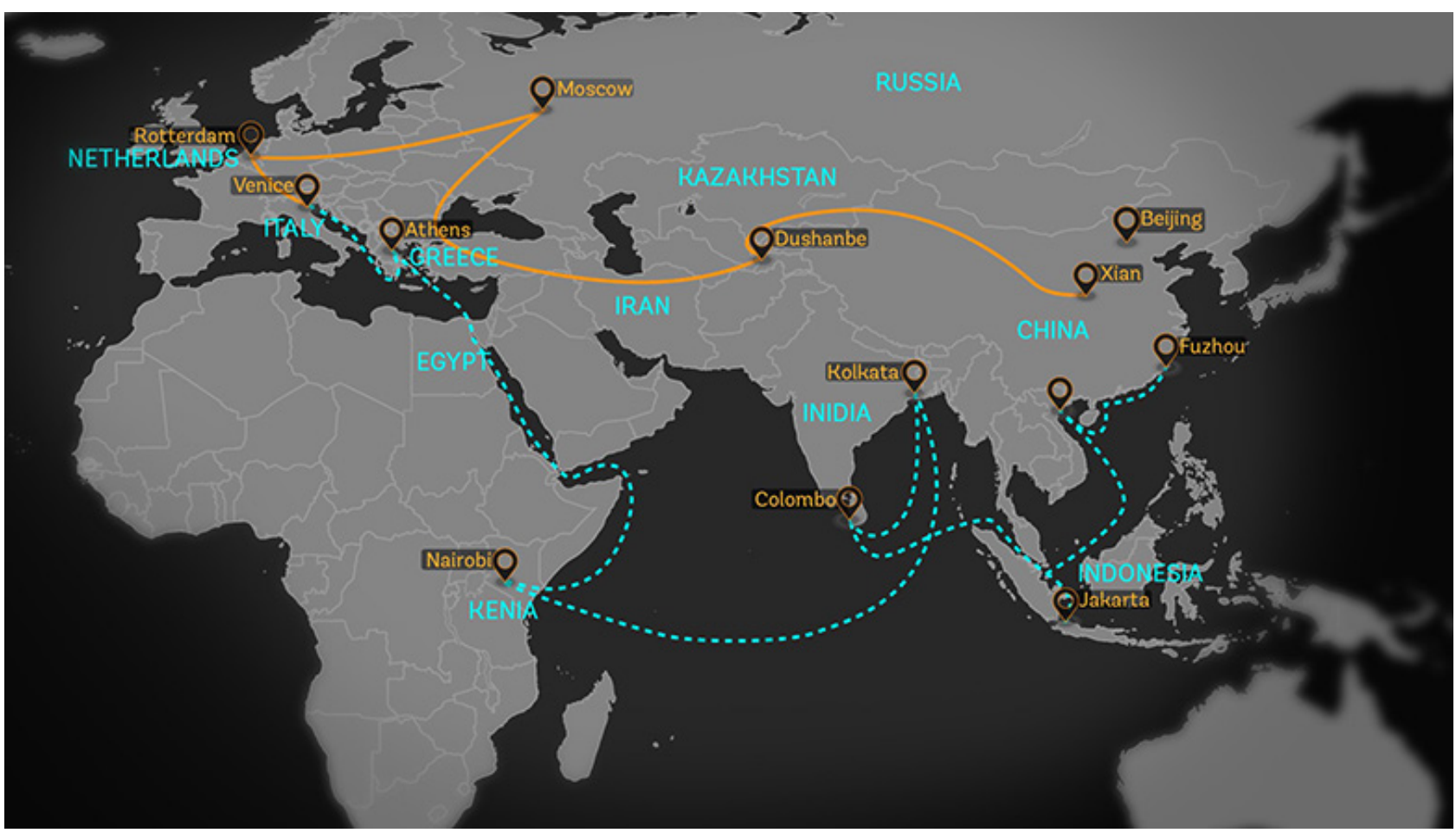

Fonte: Banco Mundial

Trata-se de um processo de integração, diferente do paradigma neoliberal, centrado na produção/comércio via os "cinco fatores de conectividade”, nomeadamente: a) comunicação política; b) conectividade de infraestrutura; c) comércio desimpedido; d) circulação monetária; e) entendimento entre pessoas (YIWEI, 2016). Ademais, cumpre diversos objetivos articulados para a China como, primeiro e imediatamente, criar demanda para a supercapacidade ociosa da indústria nacional. Segundo, ampliar a segurança em recursos naturais e alimentares, sobretudo energéticos, evitando o eventual estrangulamento em estreitos - chamado de Dilema de Malaca por Hu Jintao em 2003. Terceiro, impulsionar a internacionalização das empresas chinesas e a exportação de serviços (de engenharia, especialmente). Quarto, fortalecer o comércio regional e o papel gravitacional da China, recriando o sistema sinocêntrico. Quinto, estabilizar e securitizar a partir do desenvolvimento e da integração regionais. Sexto, fomentar a conversibilidade ao remimbi (RMB) tornando a moeda chinesa reserva de valor e meio de comércio corrente. Por esta razão, sugerimos que se trata de um projeto chinês de globalização compartimentado em 3 círculos concêntricos (Figura 1). 
Figura 1 - Três Círculos Concêntricos do Projeto Chinês de Globalização

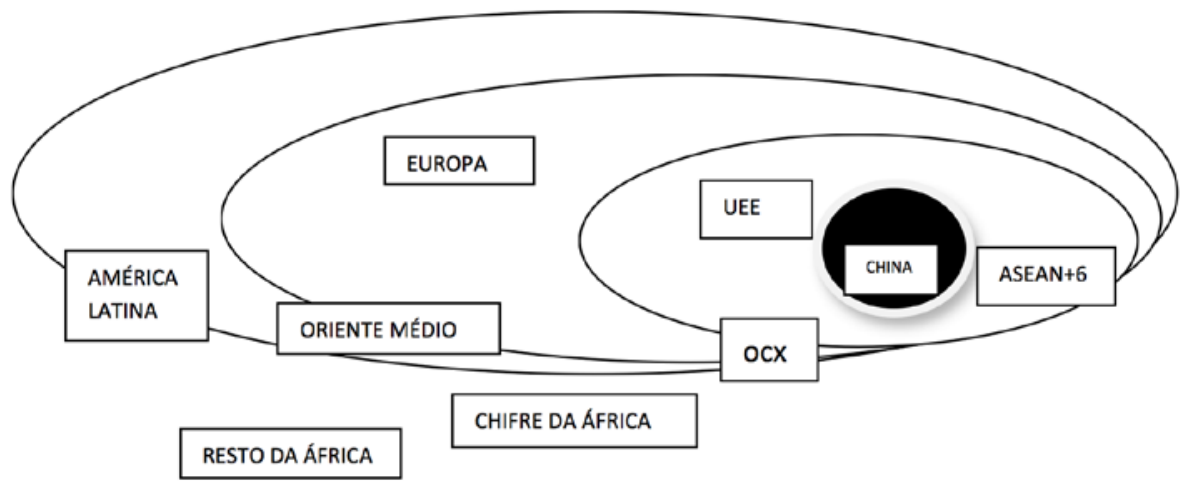

Fonte: Elaboração do autor.

Esses objetivos são impulsionados tendo como vetor da política externa chinesa as obras de infraestrutura (comunicação, transporte, energia) - cuja expertise nessa diplomacia da exportação de serviços de engenharia ocorreu primeiramente na África a partir do final da década de 1990. Ao mesmo tempo, Beijing desenvolveu capacidades para lidar com países vulneráveis e instáveis, vendo oportunidades onde outras potências prescreviam soluções institucionais descoladas da realidade de países periféricos. Como destaca Brautigam (2009), a ajuda ao desenvolvimento e a cooperação econômica da China têm práxis distintas, baseado na sua própria experiência de modernização e demandas dos países beneficiários e, portanto, centra-se em infraestrutura, produção e serviços de educação e saúde, por exemplo (BRAUTIGAM, 2009, p. 11). Ora, após de quase duas décadas de aprendizado no continente africano, o país asiático formulou essa ambiciosa iniciativa. Ao impulsionar um virtuoso processo de desenvolvimento e integração sob liderança da China, a Nova Rota da Seda tende a enfrentar desafios múltiplos também a Eurásia, com destaque para os securitários.

Entre os desafios securitários, deve-se destacar, primeiramente, aqueles decorrentes de diversos movimentos separatistas e terroristas que afetam a China, como Xinjiang, e a Rússia, como Chechênia. Ademais, por proximidade, Afeganistão, Paquistão e países da Ásia Central também são regiões irradiadoras de instabilidade em função do enraizamento do crime organizado transnacional de drogas e armas bem como de irradiação de movimentos separatistas e extremistas, como o Talibã e o Movimento Islâmico do Turquistão Oriental (ETIM). O segundo desafio se relaciona aos diversos litígios territoriais como demarcação de fronteiras na Ásia Central e a existência de enclaves disputados - como do Tajiquistão, Vorukh, no Quirguistão, enquanto este último tem um enclave de Barak no Uzbequistão e este tem os enclaves de Sokh e Shakhimardan no Quirguistão. Terceiro, não se pode subestimar a importância dos Estreitos como desafio securitário para a dimensão marítima da OBOR, sobretudo os Estreitos de Malaca, cujo controle é dos Estados Unidos, e o Estreito de Ormuz, cercado por uma deterioração da situação de segurança, como a Somália, e a pirataria (HAIQUAN, 2017), crucial para entender a presença da China no Djibuti. 
Todavia, a questão de fundo diz respeito à estratégia de Washington que se configura como uma retomada da política de contenção na Eurásia, sobretudo no entorno do eixo sino-russo. Em alguma medida, os Estados Unidos reeditam a política de contenção da Guerra Fria. Em outras palavras, os desafios securitários são centrais não apenas ao eventual êxito da Nova Rota da Seda, mas também para definir os limites de atuação internacional de China e Rússia, a penetração estadunidense na Eurásia e, sobretudo, tende a ser central nas novas configurações de poder em formação no mundo.

No caso da Rússia, a política de contenção tem assumido diversas formas articuladas. Primeiro, a lógica de expansão da Organização do Tratado do Atlântico Norte (OTAN, aliança militar do Ocidente originalmente voltada ao combate do comunismo soviético) que mais do que dobrou o número de integrantes apesar do fim da URSS e da bipolaridade. A OTAN tem se fortalecido e ampliado a agenda política de atuação e seu escopo geográfico. Foram integrados os Países da Europa Central e do Leste (PECL), tais como Hungria, Polônia e República Checa (1999); Bulgária, Estônia, Letônia, Lituânia, Romênia, Eslováquia e Eslovênia (2004); Albânia e Croácia (2009); e Montenegro (2017). ${ }^{11}$ Além de intervenções fora do domínio dos países membros (Balcãs, Afeganistão, Líbia, etc.), as ambições têm sido reiteradas sobre o espaço ex-soviético, como Geórgia e Ucrânia. Aliás, tanto a guerra de 2008 no primeiro país, quanto àquela iniciada em 2014 no segundo, não podem ser compreendidas sem levar em conta a obsessão dos Estados Unidos e seus aliados de ampliar o cerco à Rússia. Segundo, existe uma política de absorção do espaço econômico de influência da antiga URSS. Por um lado, isso tem ocorrido não somente por uma expressiva expansão direta da União Europeia (UE) em direção ao Leste Europeu, cujo número de membros passou de 15 para 28 membros, a grande maioria do antigo bloco socialista. Por outro, a UE cria política de auxílio ao desenvolvimento dos demais países do entorno regional vinculado a um conjunto de condicionalidades para estes países orbitarem os interesses de Bruxelas.

Terceiro, numa clara evidência da política de contenção à Rússia, Washington tenta anular as capacidades russas através de acordos com Polônia e República Tcheca para a instalação de radares e sistema antimísseis. Obviamente, a resposta de Moscou inclui o desenvolvimento de novas armas capazes de superar qualquer escudo ${ }^{12}$ - Sistema pesado de mísseis intercontinentais, míssil de cruzeiro e veículos subaquáticos não tripulados ambos com propulsão nuclear e sistemas de mísseis hipersônicos - e inclusive ameaça de posicionar mísseis em Kaliningrado, na fronteira com a Polônia. Quarto, deve-se levar em conta o intervencionismo militar no seu entorno desde a desintegração da Iugoslávia até a Guerra Global ao Terror, com a invasão do Afeganistão, passando pelas 'revoluções coloridas' (Sérvia 2000, Geórgia 2003, Quirquízia 2005 e Ucrânia 2004-14), com a declaração da Guerra Global ao Terror e a construção de base aérea uzbeque de Khanabad e o aeroporto de Manas, na Quirguízia. A isso soma-se a Guerra na Síria e o cerco ao Irã, cujos efeitos securitários sobre a Rússia são evidentes.

Por fim, na política de embargos ao comércio russo. É assim que se enquadra a lógica de criar atritos e ameaças na fronteira russa e esperar respostas afirmativas como forma de forjar uma espécie de russofobia no Ocidente, isolando o gigante eurasiano a partir de um discurso de Nova
11. Ver informações do site oficial da OTAN, disponível em: https://www. nato.int/cps/ie/natohq/topics_52044. htm.

12. Ver detalhes na reportagem da BBC, disponível em: https://www.bbc.com/ portuguese/internacional-43258300. 
13. Tais ideias aparecem detalhadas em outro artigo, ver Pautasso (2014).

14. Ver dados oficiais no United States Census Bureau, disponível em: https:// www.census.gov/foreign-trade/balance/c5700.html\#2016 15. Dados do Banco Mundial.

16. Para mais detalhes, ver Pautasso Doria (2017).
Guerra Fria. A vilanização da Rússia tem como objetivo último evitar a formação de um heartland baseado num eixo Berlim-Moscou-Beijing completamente fora do controle de Washington. ${ }^{13}$

Com a China não tem sido muito diferente. Embora com sinérgica relação econômica com os Estados Unidos, cuja corrente comercial alcançou US\$ 505,4 bilhões em 2017, o cerco vem crescendo à medida que a potência asiática fortalece seus poderes econômico e político. As vantagens comerciais chinesa sobre os estadunidenses são notáveis e crescentes, não apenas pelos seus superávits de US\$ 375,5 bilhões ${ }^{14}$ no comércio bilateral, mas na comparação de exportações de produtos de alta tecnologia em 2016, cujas exportações dos chineses foram de 496 bilhões, antes 153 bilhões de dólares dos estadunidenses. ${ }^{15}$

Nesse sentido, a 'guerra comercial' encampada por Trump em 2018 representa o recrudescimento das intermitentes disputas sino-americanas nesse campo, refletindo a perda de competitividade dos Estados Unidos e os compromissos de seu atual presidente com setores produtivos nacionais. No entanto, cabe ressaltar que a China não é o Japão do Acordo Plaza (1985) - quanto a ilha foi submetida a apreciação de sua moeda e, com efeito, empurrada à desaceleração econômica e subsequentes bolhas nos preços imobiliários e crise bancária. Ao contrário, Beijing dispõe de diversos meios de resistir e retaliar, dada as dimensões de seu mercado doméstico, diversificação do comércio exterior, poder diplomático-militar, reservas internacionais (em dólar), entre outros meios. Nesse sentido, a guerra comercial desencadeada pelos Estados Unidos contra a China em abril de 2018 representa o recrudescimento de disputas cujas origens remontam às tentativas de vetar o ingresso de Beijing na Organização Mundial do Comércio (OMC) ainda nos anos 1990.

Ademais, os Estados Unidos exploram litígios territoriais que envolvem a China para justificar sua presença na região e ingerir em temas de interesse de Beijing. Os movimentos de Washington de apoio recorrentes a forças políticas independentistas e as vendas de armas a Taiwan; o fomento, a partir de seus aliados, dos litígios no Mar do Sul ${ }^{16}$ da China, sobretudo nas ilhas Spratly; a solidariedade ao Japão nas disputas pelas ilhas Senkaku/ Diaoyu; e o apoio externo aos movimentos separatistas do Tibet e do Xinjiang. Esse último caso se entrelaça às ações da Casa Branca voltadas a denunciar a China por abusos de diretos humanos em diversos âmbitos político-diplomáticos. A presença estadunidense na Bacia do Pacífico se completa com sua ampla assertividade militar em países como Coreia do Sul, Japão, Tailândia, Malásia e Filipinas, além de bases em Guam e Havaí e o anúncio de construção de escudo antimíssil THAAD na Península Coreana - percebida por Beijing como ameaça a sua capacidade militar dissuasória.

Assim, se entrelaçam intervenções 'humanitárias', imposição de 'democracia de mercado', isolamento de 'Estados parias', expansionismo baseado na guerra ao terror, drogas e/ou corrupção, ataques preventivos, guerras por procuração, sistemas globais de espionagem, etc. (JOHNSON, 2007, p. 31), Como disse Engdhal (2009, p. 127), o império de bases militares é a base do Império e sua política de full spectrum dominance.

Essas são as bases de uma espécie de arco de contenção do eixo sino-russo liderado pelos Estados Unidos baseado em múltiplas estratégias. Inclui o avanço de alianças militares, como a expansão da OTAN, bem como uma gigantesca estrutura de projeção de força militar que cobre a 
Eurásia, compostas pelos Comando do Pacífico (PACOM), Comando Europeu (EUCOM) e o Comando Central (CENTCOM) e um conjunto de aliados estratégicos. Ademais, há, de cerca de 800 bases militares espalhadas pelo mundo, uma rede de bases militares estratégicas na Eurásia na Coreia do Sul, Japão, Guam, Tailândia, entre outros. Deve-se sublinhar ainda aliados regionais estratégicos, tais como Japão, Arábia Saudita, Azerbaijão, Geórgia, Israel, etc. Os casos de Índia e Paquistão, por exemplo, oscilam entre a aproximação com Washington e com o eixo-sino-russo: por um lado o acordo nuclear indo-americano (2005) e a condição de Major non-NATO Ally (2004), respectivamente, e, por outro, a inclusão como membros da OCX. A isso, somam-se as políticas de regime change através de desestabilizações como as 'revoluções coloridas', ocorridas na Sérvia (1999), Geórgia (2003), Ucrânia (2004-14), Quirguistão (2005). Sem esquecer das intervenções militares diretas, cujos efeitos foram devastadores, como Afeganistão, Iraque, Líbia e Síria - essa salva pelo apoio russo. Há ainda os países sob sanções e recorrentes ameaças militares, os casos de Coréia do Norte e Irã -inclusive com a implosão unilateral do acordo nuclear com o país persa. Outro vetor de ingerência e desestabilização são os apoios aos movimentos separatistas na Chechênia, no Tibet, no Xinjiang e de países vizinhos, como na região do Baluchistão. Por fim, mas não menos importante, há litígios envolvendo com potencial para promover uma escalada militar, como são os casos de Taiwan, Mar do Sul da China, Península Coreana, entre outros. Ou seja, o arco começa na Ucrânia, passa pelo Cáucaso, atravessa o Oriente Médio e a Ásia Central, e culmina no Sudeste e Leste Asiáticos (MAPA 3).

\section{MAPA 3}

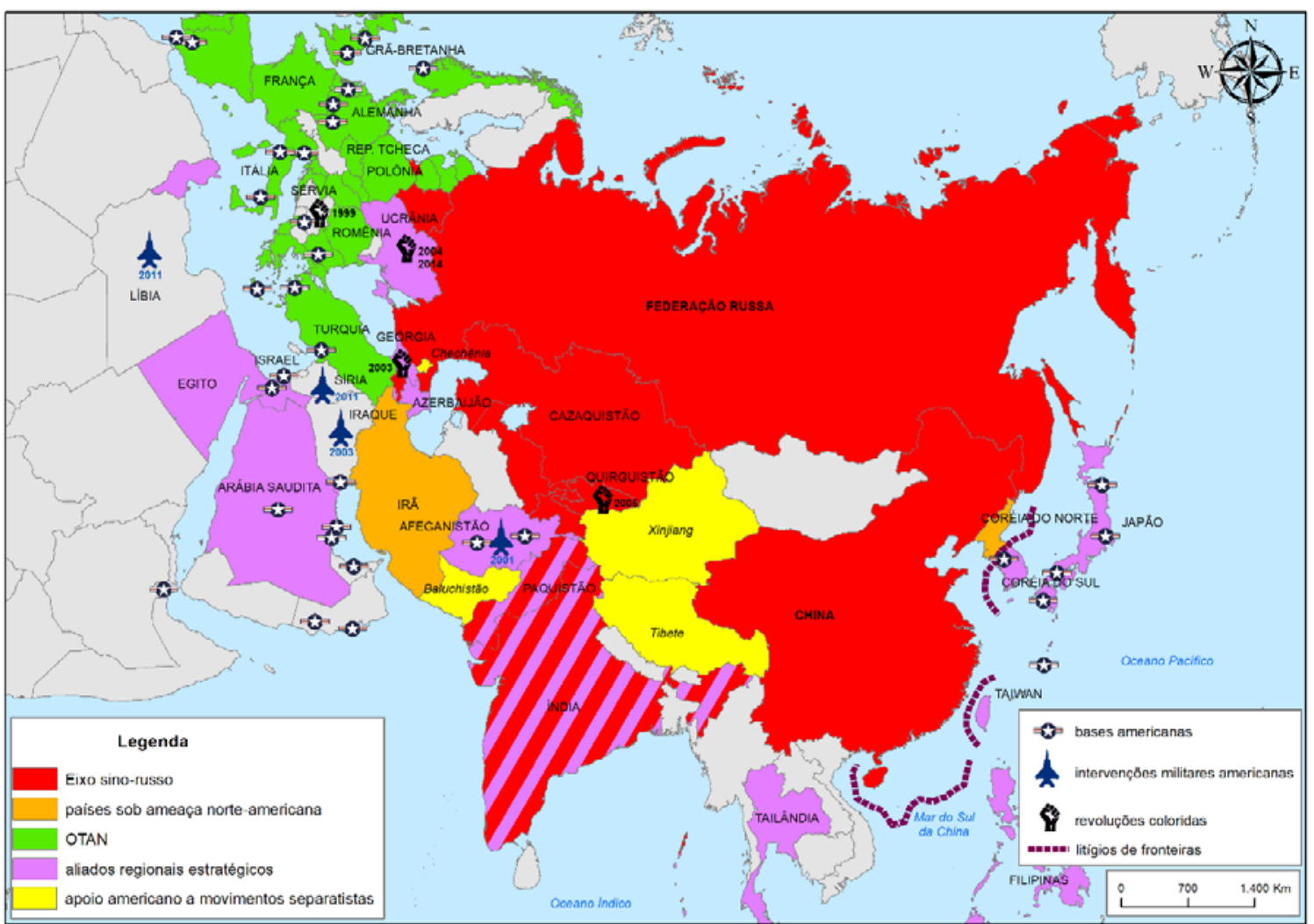

Fonte: Elaboração do autor (apoio técnico do geógrafo Tito Lívio Barcellos). 
Há um curioso paralelo entre os casos de China e Rússia: a estratégia dos Estados Unidos é expandir suas estruturas de poder, caso da OTAN contra a Rússia e da presença militar no Mar do Sul da China; se chineses e russos não reagirem, ficam acantonados e cercados, e com seu espaço de defesa diminuído; se reagirem, fomentam a percepção de expansionistas nos vizinhos e fraturam os processos de integração regionais. Em outras palavras, as políticas de contenção dos Estados Unidos para lidar com a aproximação (com tensões e contradições) entre China e Rússia são alguns dos elementos mais importantes da nova ordem mundial em gestação.

Se, por um lado, Washington recrudesce sua presença na Ásia, por outro, não são poucas as iniciativas de China e Rússia para lidar com esses e outros desafios securitários. Primeiramente, o objetivo tem sido a recuperação do poder militar russo (herdado do período soviético) e a modernização da defesa chinesa como política de dissuasão e garantia da soberania e segurança nacionais. Além das iniciativas nacionais, China e Rússia têm liderado processos de integração em sua dimensão securitária. Como destaca Haiquan (2017), a OCX (2001) nasceu com propósitos de segurança regional, notadamente a luta contra os três males (separatismo, terrorismo e fundamentalismo) e soube lidar com disputas regionais fronteiriças e criar confiança militar entre os membros. Na mesma direção, da Organização do Tratado de Segurança Coletiva (CSTO) foi impulsionada pela Rússia para ser a dimensão coletiva da CEI em 1992 (embora somente ratificado em 2002), incluindo Armênia, Bielo-Rússia, Cazaquistão, Quirguistão e Tadjiquistão - pois Azerbaijão e Geórgia se retiraram em 1999. E, por fim, a própria ASEAN tem criados vários mecanismos de segurança no Sudeste Asiático, como o Fórum Regional da ASEAN e o Conselho de Cooperação em Segurança no Pacífico Asiático (CSCAP), entre outros (HAIQUAN, 2017).

No fundo, trata-se de disputas geopolítica e geoeconômica no seio das novas configurações de poder, colocando em confronto tipos de Estado e modelos de desenvolvimento distintos. Há um nítido recuo da "grande divergência", criadora de uma brutal assimetria entre o Ocidente desenvolvido e o resto do mundo entre 1820 e 1950, e um acelerado "emparelhamento" cujos desdobramentos sobre a balança de poder será inevitável - apesar da situação delicada dos países menos desenvolvidos (NAYYAR, 2014). A Rússia e sobretudo a China buscam, não sem contradições e especificidades, o caminho do desenvolvimento. Por um lado, a China atual representa a superação do "século de humilhações" ocorrida após às Guerra do Ópio promovida pelo entrelaçamento do imperialismo britânico, japonês e estadunidense, sobretudo. Um país disposto a resistir às políticas neoliberais promovidas pelo "Consenso de Washington", ao mesmo tempo que erige o seu Estado de Bem Estar Social - em condições históricas, geográficas e demográficas inéditas. Por outro, segundo Djankov (2015), a Rússia transita de um capitalismo crônico com Yeltsin para um capitalismo de Estado sob Putin, cuja reconstrução nacional e liderança regional são notáveis. 
Consideracõos finais

A transição sistêmica empurra o mundo para choques em múltiplas dimensões. A inflexão conservadora na América Latina, o recrudescimentos da política internacional dos Estados Unidos, a multiplicação de estados falidos após intervenções apoiadas de fora (Afeganistão, Iraque, Líbia), as crises humanitárias e migratórias, o fortalecimento da xenofobia e de forças centrífugas na Europa, o crescimento de tensões em diversas regiões da Ásia-Pacífico (Mar do Sul, Península Coreana) aumentam os riscos de escaladas militares, agudizados por uma crise econômica mundial iniciada em 2008 no epicentro do sistema e pela perda de legitimidade das democracias e instituições no Ocidente. O predomínio da irracionalidade e do reacionarismo, típicos sintomas da transição sistêmica, se entrelaça aos novos potencias da Revolução Científico-Tecnológica e das novas configurações de poder que emergem em torno do eixo sino-russo e da Nova Rota da Seda.

Os desafios securitários da Nova Rota da Seda representam não apenas um obstáculo para a integração eurasiática, mas também para a ascensão da China e para a reconstrução da Rússia. Mais importante, o renascimento da Ásia e a nova ordem mundial em gestação dependem do nível de conflitividade no entorno da Eurásia e, sobretudo, nas formas de acomodação entre a potência estabelecida (Estados Unidos) e a outra emergente (China).

Bibliografia

AMIN, Samir. Os desafios da mundialização. Aparecida-SP: Idéias \& Letras, 2006.

ARRIGHI, Giovanni. Adam Smith em Pequim. São Paulo: Boitempo, 2008.

ASHLEY, Richard. The poverty of neorealism. In: KEOHANE, Robert. Neorealism e its critics. New York: Columbia University Press, 1986.

BANDEIRA, Luiz. A Segunda Guerra Fria. Rio de Janeiro: Civilização Brasileira, 2013.

BANDEIRA, Luiz. A desordem mundial. Rio de Janeiro: Civilização Brasileira: 2016.

BRAUTIGAM, Debora. Dragon's Gifts. New York, Oxford University Press, 2009.

BRZEZINSKI, Zbiginiew. EUA x URSS: o grande desafio. Rio de Janeiro: Nórdica, 1987.

CASARA, Rubens. Estado Pós-Democrático. São Paulo: Civilização Brasileira, 2017.

CASTELLS, Manuel. A sociedade em rede. São Paulo: Paz e Terra, 1999.

DIAMOND, Jared. Armas, germes e aço. Rio de Janeiro: Record, 2009.

DJANKOV, Simeon. Russia's Economy under Putin: From Crony Capitalism to State Capitalism. In: Policy Brief. Peterson Institute for International Economics, p. 1-8, set. 2015.

ENGDAHL, Frederick. Full Spectrum Dominance. Boxboro: Progressive Press, 2009.

FRIEDMAN, Thomas. O mundo é plano. Rio de Janeiro: Objetiva, 2009.

JOHNSON, Chalmers. As aflições do Império. Rio de Janeiro: Record, 2007.

HAIQUAN, Liu. The Security Challenges of the "One Belt, One Road" Initiative and China's Choices. In: CIRR. XXIII, v. 23, 78, p. 129-147. 2017.

HOFFMAN, Frank. Conflict in the $21^{\text {st }}$ century: the rise of hybrid war. PotomacInstitute for Policy Studies, Virginia, 2007.

KENNEDY, Paul. Ascensão e queda das grandes potências. Rio de Janeiro: Campus, 1989.

KIERNAN, Victor. Estados Unidos: o novo imperialismo. Rio de Janeiro: Record, 2009.

KISSINGER, Henry. Diplomacia. São Paulo: Francisco Alves, 1997. 
KORYBKO, Andrew. Hybrid war: the indirect adaptive approach to regime change. Moscou: Peoples' Friendship University of Russia, 2015

KUMAR, Krishan. Da sociedade pós-industrial à pós-moderna. Rio de Janeiro: Zahar, 1997.

LEVY, Pierre. Cibercultura. São Paulo: Edições 34, 1999.

LINKLATER, Andrew. The transformation of political community. Columbia: South Carolina Press, 1998.

LIU, Xinru. The Silk Road in World History. Oxford University Press: New York, 2010.

LOSURDO, Domenico.A esquerda ausente. São Paulo: Anita Garibaldi, 2016.

LOSURDO, Domenico. A linguagem do Império. São Paulo: Boitempo, 2010.

MAPA Shanghai Cooperation Organization. Disponível em: $<$ https://thetruthsource.org/timeline-of-shanghai-cooperation-organization-sco/>

MAPA Banco Mundial, Disponível em: https://www.worldbank.org/en/topic/regional-integration/brief/belt-and-road-initiative

NAYYAR, Deepak. A corrida pelo crescimento. Rio de Janeiro: Contraponto, 2014.

PAUTASSO, Diego. Da política de contenção à reemergência. In: Revista Austral, v. 3, n. 6, p. 73-94. 2014.

PAUTASSO, Diego; DORIA, Gaio. A China e as disputas no Mar do Sul: o entrelaçamento entre dimensões regional e global. In: Revista de Estudos Internacionais, v. 8, n. 2, 2017, p. 18-32.

PIELLA, Guillem. ¿El auge de los conflitos híbridos? In: Documento de Opinion - Instituto Español de Estudios Estratégicos. p. 1-13, 24 out. 2014.

SERRANO, Pedro. Autoritarismo e golpes na América Latina - Breve ensaio sobre jurisdição e exceção. São Paulo: Alameda Editorial, 2016.

SANTOS, Wanderley. A democracia impedida. São Paulo: FGV, 2017.

TRENIN, Dmitri. The end of Eurasia. Washington: Carnegie Endowment for International Peace, 2002.

VASYLIEVA, Nataliya; LAGUTINA, Maria. The Russian Project of Eurasia Integration. Rowman \& Littlefield Publishing, Maryland, 2016.

WEINER, Tim. Legado de Cinzas. Uma história da CIA. Rio de Janeiro: Record, 2008.

YIWEI, Wang. The Belt and Road Initiative. Beijing: New World Press, 2016. 